\title{
Biomechanical Analysis of Backstroke Start Movement in Indonesian Swimming Athletes in the 14-Year Age Group
}

\author{
Rumi Iqbal Doewes
}

Sebelas Maret University, Surakarta 57126, Indonesia

Corresponding Author Email: king.doewes@staff.uns.ac.id

https://doi.org/10.18280/mmep.070201

Received: 10 January 2020

Accepted: 18 March 2020

\section{Keywords:}

biomechanics, start, backstroke, swimming

\begin{abstract}
A good swimming start was contributed to the encouragement that swimmers can used this. The start contributed $10 \%$ from the amount of time on a swimming competition with distance 50 meters. The study purpose was analyzed the backstroke movement of Indonesian swimming athletes in the 14-year age group including the distance of jumps, impulses, travel time in the air, the take off angle, the angle of knee at the start block, and angle of fall. Type of qualitative research with a descriptive analysis approach. The sample are 3 swimming athletes. Data was taken by recording the backstroke swimming start movement and then analyzed with dartfish software and looking for the amount of impulse produced. Motion analysis shown that the backstroke start technique performed by swimmer 3 is better than swimmer 1 and swimmer 2 because it results longer jump distances, greater impulses and shorter air travel time. The starting technique was performed with the knee angle at the start block at $34^{\circ}$, the take off angle at $22^{\circ}$, the falling angle at $38^{\circ}$ resulting jump distance of $255.90 \mathrm{~cm}$, an impulse of $2.5057 \mathrm{Ns}$, and a travel time in air 48 seconds.
\end{abstract}

\section{INTRODUCTION}

\subsection{Background}

Swimming is a sport that is carried out in the water by moving the whole body on the surface of water. Swimming is aquatic in which the body pushed with movement the arms and legs [1]. The swimming competition can be divided into four main elements, is start, feedback, finish, as well as free swimming components [2]. Every component used a technique mastery of mechanical adaptation to improve certain aspects that lead to race swimming more efficient [3].

The backstroke swimming is a movement cyclic. So, the average velocity represents the best swimming performance given by intermediate results stroke rate and stroke length. Backstroke can maintain a horizontal position by a long period of time [4]. In the backstroke start, the swimmer's toes must be under the swimming start block when starting with both hands touching the start block handle. Backstroke start are athletes start from a position feet which is bent on the walls of the pool and then extend ankle, knee, hip and back to push [5]. Swimmers place their feet in line with their legs which are narrower than shoulder width or often called the standard start. Staggered foot position similar to track start can increase horizontal distance and repulsion speed compared to standard or parallel feet placement. There are four type backstroke starting position on auditory signal i.e. (1) hands on a handle horizontal highest and feet above a wedge positioned, (2) hands on a handle vertical highest and feet above a wedge positioned, (3) hands on a handle horizontal highest and feet a without wedge positioned, (4) hands on a handle vertical highest and feet a without wedge positioned [6]. The good start will give a good contribution to the speed of swimmers and will determine a champion swimmer.

Start in swimming match has become a key factor in race outcome with performance start represent between $0.8 \%$ and $26.1 \%$ of race finish time [7]. Start will help swimmers to get high achievements if done well and correctly. Factors mechanics needed to improve performance in phase start and characteristic of movement start swimmer [8]. This movement throws the weight point forward outward from the base of the support and causes the body to fall due to the earth gravity which results a fast start. This gives a threefold advantage in the start. A good leg position to be able to go strong, namely by knee bending must be in accordance with the leg muscles strength. The arm must be swung forcefully forward above the head to increase the thrust of the back leg and provide momentum to the body.

In swimming start, swimmer must apply force great quickly to start block to maximize velocity vertically on takeoff, as a result of swimmers can travel horizontally in the air before emptying into the water. This is consistent with the relations between impulses and momentum, in which impulse (the result of force and time) is necessary to produce of change of momentum (i.e. velocity) [9]. This is in accordance with Newton's second law and principle that passage momentum is passed to the whole. The body must be completely straightened and leave the starting wall almost in a horizontal plane. This will throw the body at the farthest distance before entering the water. The angle of entry of the body into the water must be made as sharp as possible so that the direction of the horizontal force is possible. This angle will depend on the height of the starting wall surface on the water surface and the resistance of swimmers. Therefore every swimmer must determine this angle by himself through experiments. Swimmers should avoid falling horizontally to the water. The 
hand must touch the water first. The head must stay between the arms to reduce resistance.

\subsection{Research purpose}

The study purpose was analyzed the backstroke movement of Indonesian swimming athletes in the 14-year age group.

\section{METHOLOLOGY}

\subsection{Research methods}

The study was carried out qualitative methods. Qualitative methods with descriptive analysis approaches can be used both effectively and efficiently to encourage and analyze participant reflections [10]. This study analyzed the backstroke starting which includes the distance of jumps, impulses, travel time in the air, take off angle, knee angle at start block, and the fall angle.

\subsection{Research samples}

The research sample consisted of 3 athletes selected by purposive sampling technique. Sample criteria includes of male, mastering the backstroke start techniques, and aged between $13-15$ years.

\subsection{Data collection}

Data collected by implementation of video capture of backstroke start used a digital camera.

\subsection{Data analysis}

Motion analysis was carried out with the dartfish software and then look for the magnitude of the impulses produced with the following formula:

$$
\begin{aligned}
& \mathrm{I}=\int_{\mathrm{t}_{1}}^{\mathrm{t}_{2}} \mathrm{Fdt} \\
& \text { Notes: } \\
& \mathrm{I} \quad=\text { Impuls (N.s) } \\
& \mathrm{F} \quad=\text { Force (N) } \\
& \mathrm{dt} \quad=\text { Time derivative [11] }
\end{aligned}
$$

\section{RESULTS}

\subsection{Data description}

Table 1 shown the difference in the results of each swimmer's jump. Swimmer 3 has the farthest jump distance. Table 1 shown a description of the measurement data of the implementation of the backstroke start which becomes a temporary picture, then performed motion analysis with dartfish software.

Table 1. Measurement results of backstroke start implementation

\begin{tabular}{ccccc}
\hline Variable & & Swimmer 1 & Swimmer 2 & Swimmer 3 \\
\hline Block time angle & Knees & 650 & 340 & 340 \\
\cline { 2 - 5 } & Hands & 890 & 760 & 1100 \\
\cline { 2 - 5 } Legs & 810 & 830 & 880 \\
\hline Takeoff angle & 180 & 120 & 220 \\
\hline Travel time in the air & 52 seconds & 50 seconds & 48 seconds \\
\hline Leap distance & $254.30 \mathrm{~cm}$ & $210.43 \mathrm{~cm}$ & $255.90 \mathrm{~cm}$ \\
\hline
\end{tabular}

\subsection{Impulse}

This section explains the amount of impulse in each swimmer that affects the distance of the resulting jump.

Table 2. Swimmer's impulse

\begin{tabular}{cccc}
\hline Variable & Swimmer 1 & Swimmer 2 & Swimmer 3 \\
\hline Mass & $42 \mathrm{~kg}$ & $41 \mathrm{~kg}$ & $47 \mathrm{~kg}$ \\
\hline Distance & $2.543 \mathrm{~m}$ & $2.1043 \mathrm{~m}$ & $2.559 \mathrm{~m}$ \\
\hline Time & $52 \mathrm{~s}$ & $50 \mathrm{~s}$ & $48 \mathrm{~s}$ \\
\hline $\begin{array}{c}\text { Repulsion } \\
\text { angle }\end{array}$ & 180 & 120 & 220 \\
\hline Speed & $0.0489 \mathrm{~m} / \mathrm{s}$ & $0.0421 \mathrm{~m} / \mathrm{s}$ & $0.0533 \mathrm{~m} / \mathrm{s}$ \\
\hline Momentum & 2.0540 & 1.7255 & 2.5057 \\
& $\mathrm{~kg} . \mathrm{m} / \mathrm{s}$ & $\mathrm{kg} . \mathrm{m} / \mathrm{s}$ & $\mathrm{kg} . \mathrm{m} / \mathrm{s}$ \\
\hline Force & $0.0395 \mathrm{~N}$ & $0.0345 \mathrm{~N}$ & $0.0522 \mathrm{~N}$ \\
\hline Impulse & $2.0540 \mathrm{~N} . \mathrm{s}$ & $1.7255 \mathrm{~N} . \mathrm{s}$ & $2.5057 \mathrm{~N} . \mathrm{s}$ \\
\hline
\end{tabular}

Table 2 shown the differences in impulse results. Swimmer 3 produces greater impulses.

\subsection{Dartfish software analysis}

\subsubsection{Block time}

Block time is a phase start what is important, and during this phase there are two actions that need to be optimized namely reaction velocity to signal start and high impulses [12].

Figure 1 shown the block time of each swimmer. Swimmer 1 performs a backstroke block start time with a knee angle of $65^{\circ}$, hand angle of $89^{\circ}$, and leg angle of $81^{\circ}$. Swimmer 2 performs backstroke block time start with knee angle of $34^{\circ}$, hand angle of $76^{\circ}$, leg angle of $83^{\circ}$. Swimmer 3 performs backstroke block time start with knee angle of $34^{\circ}$, hand angle of $110^{\circ}$, and leg angle of $88^{\circ}$. The knee angle is important for strong balance and repulsion. The knee angle was determined from a position the malleolus lateral, greater trochanter, as well as lateral epicondyle in the femur [13].

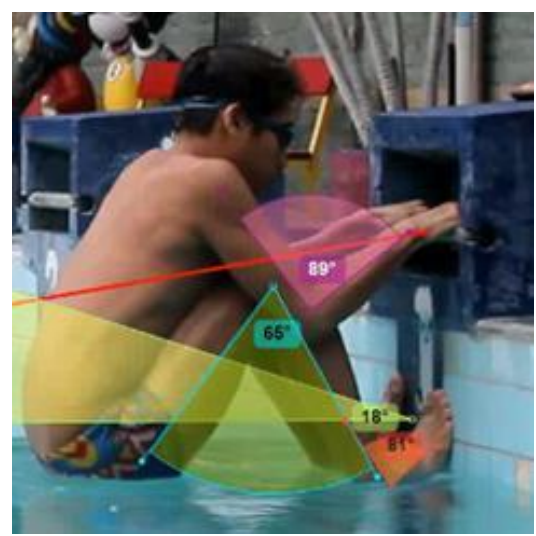

(a) Swimmer 1 


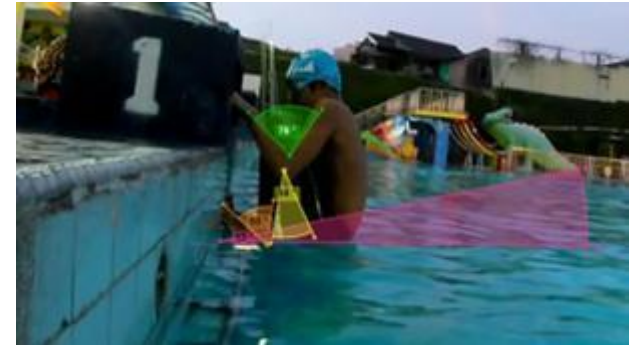

(b) Swimmer 2

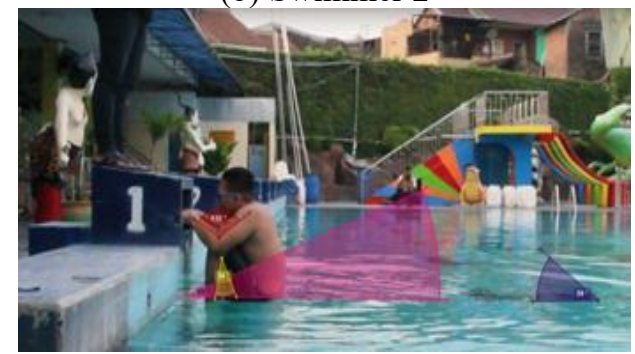

(c) Swimmer 3

Figure 1. Block time

\subsubsection{Flight time (take off)}

Take off was done with the legs refused to the pool wall with the handrails released, along with bouncy body repulsion backward so that the body hovers above the water surface. The high takeoff angle results in a steeper body entry into the water and reduces the time taken in the air [14].

Figure 2 shown the flight time of swimmer 1 with takeoff angle of $18^{\circ}$ resulting an air travel time of 52 seconds and a jump distance of $254.30 \mathrm{~cm}$.

Figure 3 shown the flight time of swimmer 2 with takeoff angle of $12^{\circ}$ resulting an air travel time of 50 seconds and a jump distance of $210.43 \mathrm{~cm}$.

Figure 4 shown the flight time of swimmer 3 with takeoff angle of $22^{\circ}$ resulting an air travel time of 48 seconds and a jump distance of $255.96 \mathrm{~cm}$.

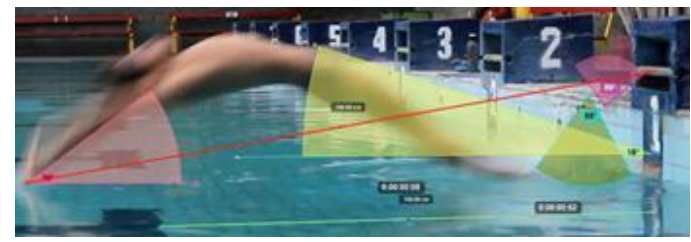

(a) Take off

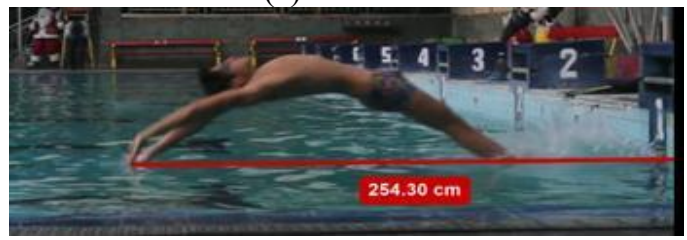

(b) Jump distance

Figure 2. Flight time of swimmer 1

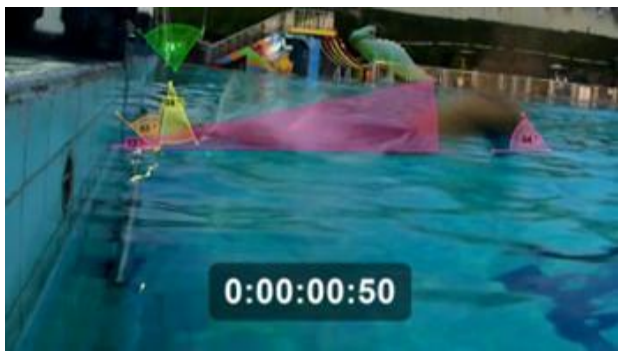

(a) Take off

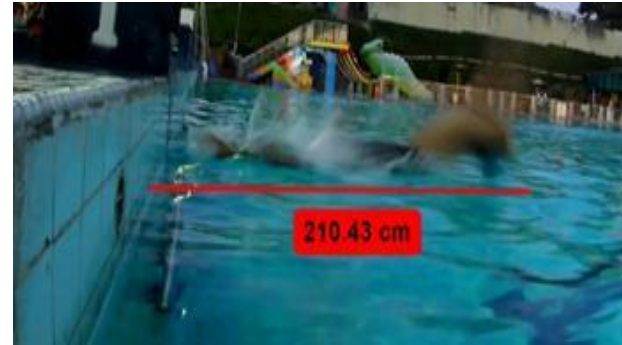

(b) Jump distance

Figure 3. Flight time of Swimmer 2

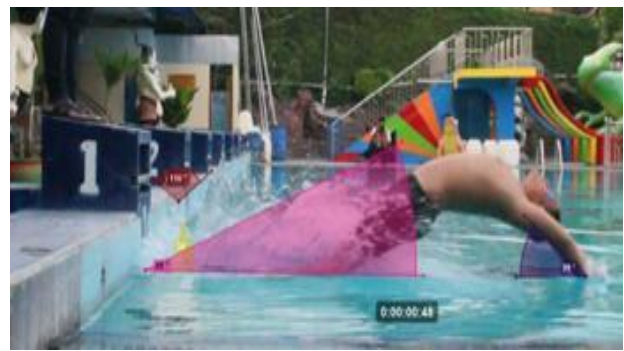

(a) Take off

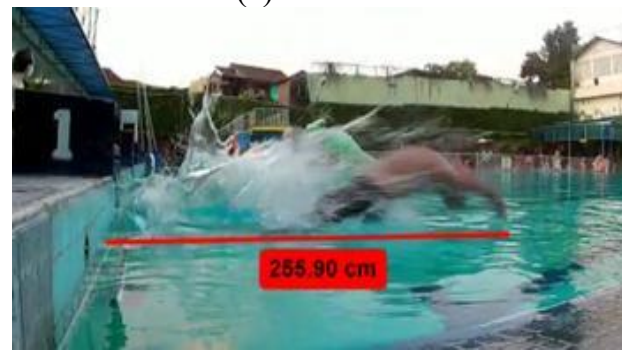

(b) Jump distance

Figure 4. Flight time of Swimmer 3

\subsubsection{Water time}

Water time is the final stage of the start. Starting from the body enter the water until the time when the body starts to stop.

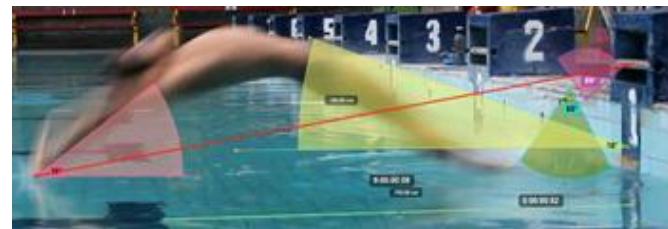

(a) Swimmer 1

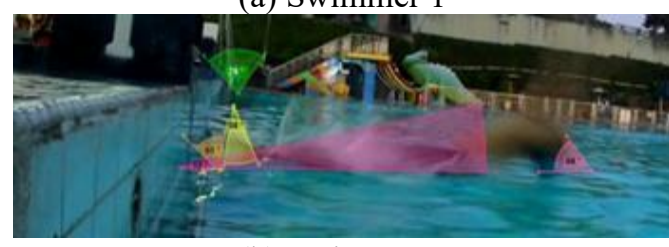

(b) Swimmer 2

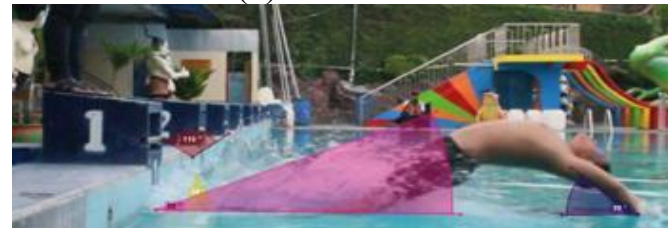

(c) Swimmer 3

Figure 5. Angle of fall

Figure 5 shown angle of fall each swimmer which is the water time stage. Hand angle of swimmer 1 is $36^{\circ}$. Hand angle of swimmer 2 is $34^{\circ}$. Hand angle of swimmer 3 is $38^{\circ}$. The 
best angle of hand entry water is the sharpest angle that a swimmer can make without making the swimmer's body fall horizontally [14]. But in the whole starting stage, the sharpest possible angle cannot be used as the optimal angle because it will not get a big jump.

\section{DISCUSSION}

Start is the beginning of the race. The good and right start will give a big share in a race. Start is said to be good and right if it produces a long slide. The slide was caused by repulsion of both legs and arm swings and movement from the body. In swimming the backstroke start is done below.

The motion analysis results shown that swimmer 3 has a longer jump distance with a shorter time and higher take-off angle. Swimmer 3 done takes off with a takeoff angle of $22^{\circ}$ and a travel time in the air of 48 seconds resulting a jump distance of $255.90 \mathrm{~cm}$. Swimmer 1 done takes off with a takeoff angle of $18^{\circ}$ and travel time in air of 52 seconds resulting in a jump distance of $254.30 \mathrm{~cm}$ and swimmer 2 done takes off with a takeoff angle of $12^{\circ}$ and travel time in air is 50 seconds resulted in a jump distance of $210.43 \mathrm{~cm}$. In theory, a high take-off angle results in steeper body into the water and less time in the air. Take off be key importance to increase distance. Swimmers at a distance of significant greater when higher take off. Found positive correlation between jump distance and take off [15]. Donations from leg repulsion affect the horizontal speed when in the air. The knee angle at the block start affects the repulsion to bring the body in the air and horizontal speed when in the air. In theory, knee angles are important for equilibrium and get strong repulsion. The back side of the lower limbs given large torque extension to absorb horizontal reactive force. The knee joint with front of the lower limbs give torque flexion a great to keep reaction force vertical to $60 \%$ time movement start normalized [16]. Swimmer 3 repulsed with a knee angle of $34^{\circ}$, swimmer 1 done a repulsion with a knee angle of $65^{\circ}$, and swimmer 2 done a repulsion with knee angle of $34^{\circ}$. The smaller knee angle that was obtained during a block start, the greater or stronger the repulsion produced. The force of leg muscles includes the quadriceps extensor, gastrocnemius, and gluteus maximus also serve to boost the forward.

The result of jumping start was also affected by the angle of entry the hand into the water (angle of fall). The greater fall angle produced by the swimmer, less the gliding in the air. The drop angle for swimmer 3 is $38^{\circ}$, while swimmer 1 is $36^{\circ}$ and swimmer 2 is $34^{\circ}$. Lower angles result in the entry of hands into water is flatter and can produce less optimal performance. The research also compatible with the finding before that significant differences in experiment each swimmer with start angle difference outcome jump furthest distance. The start motion analysis 3th swimmer outcome furthest distance with ideal angle of fall [17]. The research results support previous studies that observed the level of muscular strength of the arms, abdomen and legs affects the start of backstroke swimming. Backstroke start and countermovement jump test is statistically significant and maximum velocity test is statistically insignificant in dryland. By this research, can assess how variable strength lower limbs on an individual affect swimming performance and needed to furnish them to the other factors to make swimming training program that better [18]. The use of a computerized video method reveals and identifies the kinematics and characteristic of the principal component of the backstroke start on initial, gliding, air drift, and entering the water. Characteristic angle of main component positions of swimming backstroke start, GCG trajectory, linear velocity and angular velocity of body segments and the forces resultant seen at structured stages [19]. In other studies shown that force in after the start signal is greater when using the wedge and there was no correlation between force, time on a reference point and time at a distance $5 \mathrm{~m}$. Wedge can use force vertical but not directly during the time at a distance $5 \mathrm{~m} \mathrm{[20].}$

The start technique also affects the magnitude of the impulses that affect the take off velocity and jumping distance. The greater push causes more take off velocity, this is related to impulses and momentum. Swimmer can increase impulses by doing greater force or improve block time contact during the surface early [13]. The researchers tried to learn about swimming performance to find coordination between limbs ideal to give biomechanics profile (kinemathics and kinethics of swimming) with improve swimming performance [21]. In particular, biomechanical analysis of backstroke swimming starts to analyze a significant reduction in time at the start of the match, the first 50 meters, which is likely a result of impulses and slips after jumping from the start block [22]. An impulse is an event in which a force works in a very short time. The impulse produced by swimmer 3 is greater than swimmer 1 and swimmer 2. Swimmer 3 produces impulses of 2,5057 Ns, while swimmer 1 produces impulses of 2,0540 Ns and swimmer 2 produces impulses of 1,7255 Ns. The start technique allows swimmers to produce larger impulses without increasing the start block time will be the most optimal technique [23]. A handgrip horizontal show asymmetry force horizontal greater hand on a signal start, before hand off and impulses asymmetry. Asymmetry and resultant velocity take off on both variant that are strongly attached and on horizontal impulses feet. Kinetics lateralisation observing start backstroke and asymmetry which impede the desired performance [24].

Impulse larger during take off and transformation to movement under water quickly is a determinant factor to reduce time start on parallel and entirely submerged (BSFI). Related above water surface (BSFE), the approach mass center larger on walls can indicate flat take off angle, sacrifice speed unterwater and start performance [25]. The result of study that set of technique start done by swimmer starting from block phase, flight, and water time must be considered. Consequently, impulse on the wall to do rotate, time contact with the wall (arm and limb), and quickly pull out after open turn, which is a determining factor of success [26].

\section{CONCLUSIONS}

Motion analysis shown that the backstroke start technique performed by swimmer 3 is better than swimmer 1 and swimmer 2 because it results in longer jump distances, greater impulses and shorter air travel time. Mechanical start is done with knee angle on the block start at $34^{\circ}$, the take off angle of $22^{\circ}$, falling angle of $38^{\circ}$, that produce jumping distance as far as $255.90 \mathrm{~cm}$, impulse amounting to $2.5057 \mathrm{Ns}$, and the travel time in the air is 48 seconds.

\section{REFERENCES}

[1] Kumar, S., Kr, S., Yadav, S. (2017). Effect of selected 
swimming training program on 50mts free style performance of school boys. 125: 13-15.

[2] Thng, S., Pearson, S., Keogh, J.WL. (2018). The relationship between dry-land resistance training and start performance in competitive swimming: A brief review faculty of health sciences and medicine. ISBS Proceedings Archive, 36(1): 927-930.

[3] Exercise, I., York, K.M., Strubler, D.S., Smith, E.M. (2005). A comparison of two. 34(3): 271-281.

[4] Rejman, M., Kwaśna, A., Chrobot, M., Kjendlie, P., Stalmann, R.K. (2020). Perceived versus real swimming skills of adolescents under standard and challenging conditions: Exploring water competencies as an approach to drowning prevention. Int. J. Environ. Res. Public Health, 17(11): 3826 https://doi.org/10.3390/ijerph17113826

[5] Barkwell, G.E., Dickey, J.P. (2020). Different lowerlimb setup positions do not consistently change backstroke start time to $10 \mathrm{~m}$. Sports, 8(4): 43. https://doi.org/10.3390/sports8040043

[6] De Jesus, K., De Jesus, K., Medeiros, A.I.A., Gonçalves, P., Figueiredo, P., Fernandes, R.J., Vilas-Boas, J.P. (2015). Neuromuscular activity of upper and lower limbs during two backstroke swimming start variants. Journal of Sports Science and Medi-cine, 14(3): 591-601.

[7] Carradori, S., Burkhardt, D., Sinistaj, S., Taylor, W.R., Lorenzetti, S. (2015). Kinetic and kinematic analysis of the leg positioning in the freestyle track start in swimming. 33rd International Conference on Biomechanics in Sports, pp. 808-811.

[8] Ozeki, K., Suito, H., Sakural, S. (2018). Kinematic characteristics of kick start for elite competitive Japanese male sprint swimmers. 36th Conference of the International Society of Biomechanics in Sports, Auckland, New Zealand, pp. 386-389.

[9] Thng, S., Pearson, S., Rathbone, E., Keogh, J.W.L. (2020). The prediction of swim start performance based on squat jump force-time characteristics. PeerJ, 8: e9208. https://doi.org/10.7717/peerj.9208

[10] Sibbald, S.L., Brennan, D., Zecevic, A. (2019). Onesentence, one-word: An innovative data collection method to enhance exploration of the lived experiences. Qualitative Report, 23(12): 2253-2260.

[11] Schilling, B.K., Falvo, M.J., Chiu, L.Z.F. (2008). Forcevelocity, impulse-momentum relationships: Implications for efficacy of purposefully slow resistance training. Journal of Sports Science and Medicine, 7(2): 299-304.

[12] Marinho, D.A., Barbosa, T.M., Neiva, H.P., Silva, A.J., Morais, J.E. (2020). Comparison of the start, turn and finish performance of elite swimmers in $100 \mathrm{~m}$ and 200 $\mathrm{m}$ races. Journal of Sports Science and Medicine, 19(2): 397-407.

[13] Barkwell, G.E., Dickey, J.P. (2018). The effects of plyometric warm-up on lower limb muscle activity and time to $10 \mathrm{~m}$ in the backstroke swimming start. International Journal of Human Movement and Sports Sciences, $6(3)$ :

$55-62$ https://doi.org/10.13189/saj.2018.060302

[14] Riewald, S., Rodeo, S. (2015). Science of Swimming Faster. In Science of Swimming Faster. https://doi.org/10.5040/9781492595854
[15] Alptekin, A. (2014). Body composition and kinematic analysis of the grab start in youth swimmers. Journal of Human Kinetics, 42(1): 15-26. https://doi.org/10.2478/hukin-2014-0057

[16] Paper, C., Takeda, T. (2016). Kinetic Analysis of Start Motion on. (November), 1-4.

[17] Doewes, R.I., Purnama, S.K., Nuryadin, I., Manshuralhudlori. (2019). Analysis of swimming start angle to the sliding ability of man crawl swimming style viewed from biomechanical study. Proceedings of the 5th International Conference on Physical Education, Sport, and Health (ACPES 2019), pp. 116-123. https://doi.org/10.2991/acpes-19.2019.26

[18] Kováčová, N., Brod’áni, J. (2019). Swimming performance to 25 meters backstroke depends on selected factors of explosive strength of lower limbs. Acta Facultatis Educationis Physicae Universitatis Comenianae, 59(2): 203-213. https://doi.org/10.2478/afepuc-2019-0018

[19] Elena-Diana, S., Vladimir, P. (2019). Biomechanical characteristics of the start in backstroke swimming style in the students of higher education of other profiles. Romania The Journal Is Indexed in: Ebsco, SPORTDiscus, Index Copernicus Journal Master List, XIX(1): 37-43.

[20] Duarte, D., de Jesus, K., Gonçalves, P., Medeiros, A.I.A., Fernandes, R.J., Vilas-boas, J.P., De Jesus, K. (2017). The wedge effects on vertical force-time curve instants and on backstroke start performance. 35th Conference of the International Society of Biomechanics in Sports, Cologne, Germany, pp. 656-659.

[21] Seifert, L., Komar, J., Barbosa, T., Toussaint, H., Millet, G., Davids, K. (2014). Coordination pattern variability provides functional adaptations to constraints in swimming performance. Sports Medicine, 44(10): 13331345. https://doi.org/10.1007/s40279-014-0210-x

[22] de Oliveira, G.T., Werneck, F.Z., Coelho, E.F., de Moura Simim, M.A., Penna, E.M., Ferreira, R.M. (2019). What pacing strategy $800 \mathrm{~m}$ and $1500 \mathrm{~m}$ swimmers use? Revista Brasileira de Cineantropome-tria e Desempenho Humano, 21. https://doi.org/10.1590/1980$0037.2019 v 21 \mathrm{e} 59851$

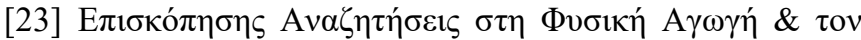

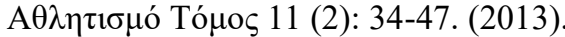

[24] De Jesus, K., De Jesus, K., Gonçalves, P., Vasconcelos, M.O., Medeiros, A.I.A., Carvalho, D.A.D., Fernandes, R.J., Vilas-Boas, J.P. (2018). Lateral kinetic proficiency and asymmetry in backstroke start per-formed with horizontal and vertical handgrips. Sports Biomechanics. https://doi.org/10.1080/14763141.2018.1522368

[25] De Jesus, K., De Jesus, K., Figueiredo, P., Gonçalves, P., Pereira, S., Vilas-Boas, J.P., Fernandes, R.J. (2011). Biomechanical analysis of backstroke swimming starts. International Journal of Sports Medicine, 32(7): 546-551. https://doi.org/10.1055/s-0031-1273688

[26] Morais, J.E., Marinho, D.A., Arellano, R., Barbosa, T.M. (2019). Start and turn performances of elite sprinters at the 2016 European Championships in swimming. Sports Biomechanics, 18(1): https://doi.org/10.1080/14763141.2018.1435713 